\title{
Optimization of Solar Dryers through Thermal Energy Storage: Two Concepts
}

\author{
Johannes. P Angula \\ Department of Mechanical Engineering \\ University of KwaZulu-Natal,Durban, South Africa.
}

\author{
Freddie L. Inambao* \\ Department of Mechanical Engineering \\ University of KwaZulu-Natal,Durban, South Africa.
}

ORCID: 0000-0001-9922-5434

\begin{abstract}
The technology of storing thermal energy is primarily based on using materials that are deemed fit for storing thermal energy which can be discharged for later usage based on the application. Different applications might require thermal energy for heating or cooling purposes; hence, a suitable energy storage material must be selected to efficiently meet the application's demand. This paper focuses on innovative ways of storing solar thermal energy that can be used in to improve the drying processes of conventional solar dryer systems used for food drying. It aims at identifying the most suitable and economical materials that can be used for the design of an optimal thermal energy storage system/unit to store energy from the sun during sunshine hours and release it during non-sunshine hours. The energy stored is aimed at prolonging the drying process and improving thermal efficiency of the solar dryer systems. The research conducted has identified two conceptual designs that are economically viable for the design and construction of a thermal energy storage system. As discussed in this paper, concept 1 utilizes a rock-bed system and concept 2 utilizes a hot water tank to store solar thermal energy. A review of different experiments on thermal energy storage materials by various researcher is also presented in this paper.
\end{abstract}

Keywords: Thermal energy storage; solar energy; materials; design; performance; cost

\section{INTRODUCTION}

Solar drying of food and agricultural products provides an effective and economical means of preserving foods in most developing countries. The drying rate can be significantly improved through the use of efficient and optimized solar drying techniques. Solar energy is unreliable due to weather conditions and other factors; however, with the use of appropriate technologies, energy from the sun can be harvested and stored for later usage. One of the effective ways to optimize solar dryer systems is by integration of a thermal energy storage (TES) system. The TES system works on the basis of a thermal energy sensitive material (liquid, solid, or phase change material) that can store solar energy captured during peak hours and release it during off-peak hours so as to prolong the drying process [1].

Recent studies indicate that solar dryers with an integrated thermal energy storage system are effective for continuous drying at a steady state in temperatures ranging from $40{ }^{\circ} \mathrm{C}$ to $60{ }^{\circ} \mathrm{C}$ [2]. TES systems are not only used in the solar drying process but are also widely used in buildings and industrial processes such as power generation [5]. Many benefits have been reported in the literature pertaining to the use of TES in energy systems such as [5, 9]:

- Improved thermal efficiency

- Reduction in the utilization of fossil fuel

- Better system reliability

- Environmentally friendly

- Improved energy security

- Improved running costs and general economic value

The ever-increasing global population results in increased food consumption leading to a situation of increased food insecurity which can be addressed through measures such as solar drying. Solar energy is considered as the most economical and feasible way of dealing with the preservation of food and agricultural products. Although solar energy is plentiful and widely accessible for usage, its availability is irregular and periodic. Solar energy is mostly dependent on weather conditions and geographical location, and it is only available during daytime. In applications where solar energy is required for drying, TES system can be employed to take advantage of the availability of solar energy in order to store it and use it when needed. This is particularly the case in regions with less average sunshine hours per day such as humid subtropical regions. Whether energy storage can be justified depends critically on the nature of the demand and supply, and the conditions of operation since some energy storage systems can be charged and discharged several times a day while others are inter-seasonal [7]. In many industrial drying processes, controlled drying uses fossil fuel. However, the use of fossil fuel for energy generation has many negative impacts such as high running cost, environmental effects, and gradual depletion of its reserve [3]. This necessitates further research on harnessing solar energy to improve the drying process and so lead to a reduction in the use of fossil fuel.

South Africa has good sunshine hours throughout the year. Most areas of the country have annual average of at least 2500 hours of sunshine while the daily solar irradiance ranges from a 
minimum of $4.5 \mathrm{kWh} / \mathrm{m}^{2}$ to a maximum of $6.5 \mathrm{kWh} / \mathrm{m}^{2}$ [4]. South Africa has a high production of agricultural products such as maize (corn). Hence, the potential of solar drying with an integrated TES system can be considered a viable option for both industrial and domestic sector of the country. TES systems are of crucial importance to any system that utilizes mainly solar energy because they compensate for the temporally mismatches during off-peak periods [6]. This paper focuses on the concept of optimizing solar dryers by incorporating a thermal energy storage unit to enhance thermal efficiency and drying of food products. In this paper a brief overview of the principles pertaining to TES systems is presented. Conceptual designs of the proposed TES unit for improvement of drying efficiency of a solar dryer are discussed.

\section{LITERATURE REVIEW}

The necessity of storing solar energy for thermal applications cannot be overemphasized; it is an important aspect of renewable energy that addresses issues of thermal energy, cost, environmental impacts, etc. Energy storage is an opportunity to optimize solar energy dependent systems by mitigating the issues of intermittence of solar energy. The storing of thermal energy in materials is divided into three temperature categories. Depending on the type of application, thermal energy can be either stored for low temperature heating (up to $90{ }^{\circ} \mathrm{C}$ ), medium temperature heating $\left(90{ }^{\circ} \mathrm{C}\right.$ to $\left.300{ }^{\circ} \mathrm{C}\right)$ or for high temperature heating $\left(300^{\circ} \mathrm{C}\right.$ to $\left.1250{ }^{\circ} \mathrm{C}\right)$ [7]. The application of solar thermal energy storage is mostly associated with low temperature heat, hence in this study, the discussion is mainly on low temperature heat applications. As shown in fig.1, solar thermal energy can be stored in three forms of thermal energy storage, namely, sensible heat energy storage, latent heat energy storage and thermochemical energy storage.

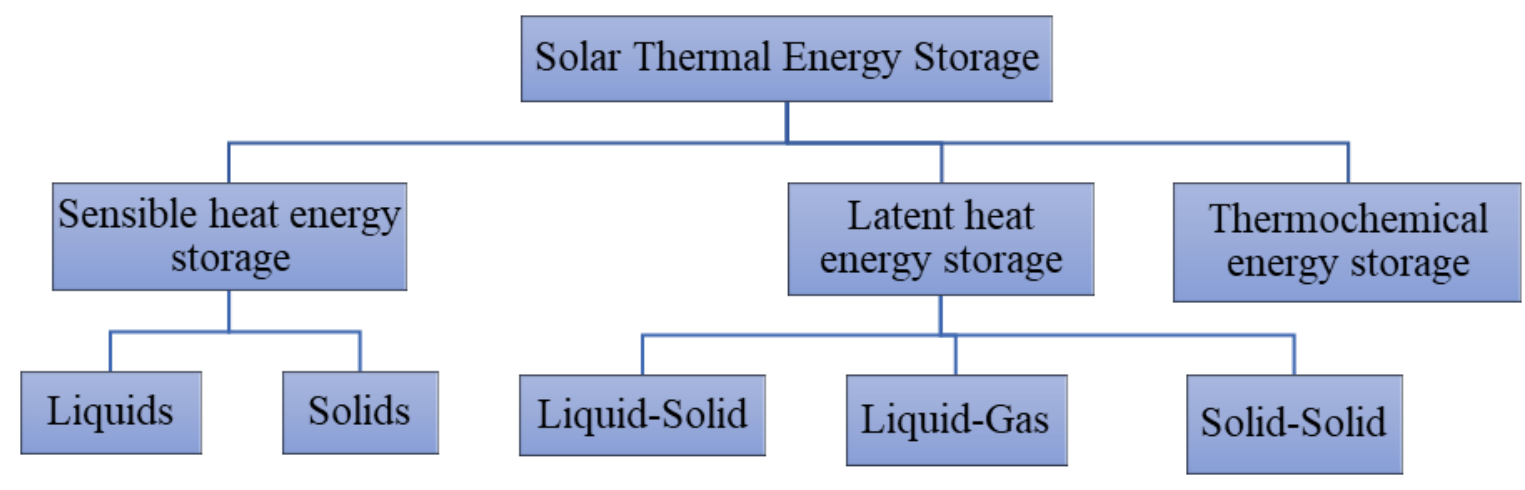

Fig. 1. Classification of TES systems of solar energy

The basic principles of these thermal energy storage systems are essentially the same. They mainly differ in their scale and energy storing method. The capacity of the storage system depends on the amount of time that the energy requires to be stored for [9]. All three energy storage systems are discussed in this paper but an emphasis is placed on sensible heat and latent heat energy storage systems because they are viable for low temperature applications.

\section{A. Properties and Characteristics of TES materials}

TES systems not only address the issues of intermittence of solar energy, but also enhance the efficiency and reliability of the entire system that requires thermal energy such as solar dryer systems [5]. Hence, careful considerations must be considered when designing a TES system for any application to ensure reliability and efficiency is enhanced. Alva et al. (2017) conducted a study on materials that are suitable for storing thermal energy. They identified various factors that need to be taken into consideration when selecting thermal energy storage materials suitable for the application. Some of the important factors to take into consideration are as follows [3,5,10]:

- Density of material - Materials with high density tend to store more energy, consequently improving the thermal efficiency of the system. TES systems designed with high density materials result in high energy storage capacity but this depends on the storage process and material/medium type. The volume of the TES system is also reduced if a high-density material is used.

- Melting point of material - In applications where a phase change material is used for storing thermal energy, its melting point is crucial and careful consideration needs to be taken when designing the energy storage system.

- Enthalpy of fusion - A high enthalpy of fusion for a phase change material indicates a high energy storage material. Hence, these materials need to have high latent heat of fusion to ensure more heat is dissipated during phase change.

- $\quad$ Specific heat capacity of a material - In applications where sensible heat energy storage materials are used, the selection must consider those with a high specific heat capacity to improve energy storage.

- Thermal conductivity - TES systems designed with energy storage materials whose thermal conductivity is high have better rates of thermal charging and discharging, a requirement for an efficient TES system. 
- Cost implications - Relates to affordability, maintenance/running cost and lifetime of the TES system. Materials need to be affordable and easily accessible.

- $\quad$ Flammability - As part of safety, careful consideration must be taken when selecting materials to avoid flammable materials.

- Thermal and Chemical stability - The lifespan of the TES system must not be significantly affected by thermal cycles as a result of heating and cooling of the material, and chemical reactions.

- Volume change - In applications where phase change materials are used, the selection must consider materials with a low thermal expansion coefficient to avoid a high change in volume during the process of phase change.

- Toxicity - As part of the health and safety issues, toxic and explosive materials need to be avoided or handled by an expert if the application requires such materials.

- Vapor pressure - Materials with low vapor pressure at operating temperatures are generally considered for the design of the TES system in order to minimize problems associated with containment and reduce costly insulation of the TES system.

- Storage duration - Relates to how long the energy can be stored in the system.

- Charging/discharging duration - Relates to the time required for charging/discharging the system.

- Congruent melting is required for phase change materials in order to have a constant storage capacity for every thermal cycle.

- Complete reversable process - For phase change material, the freezing/melting cycle must be completely reversable.

- Super cooling - For TES systems that utilizes phase change materials, the materials need to have a high nucleation rate to prevent the liquid from super cooling during the discharging

\section{B. Common TES material for low temperature applications}

Traditionally heat has been stored in sensible form by increasing the temperature of a liquid or solid. Usually a liquid or solid is used because the specific heat of gas is too low to be practically considered for thermal storage. This method is commonly practiced in many parts of the world for low temperature applications because it is inexpensive and easy to implement [11]. However, the other two TES techniques (storage of latent heat and thermochemical heat) offer better benefits because they store more energy per unit volume [7]. The following subsections give an overview of these various storage options in relation to the everyday use of energy storage applications.

1) Sensible heat energy storage. Sensible heat energy storage relies on the specific heat capacity and the temperature change of a TES material during the process of charging or discharging in which the temperature of the TES material increases when energy is absorbed and decreases when energy is withdrawn [11]. Further research indicates that the thermodynamic process during charging and discharging is completely reversable for the entire lifespan of the storage system, and it always take place under a constant pressure (mostly atmospheric pressure). Eq. 1 describes the sensible heat $\mathrm{Q}_{\mathrm{s}}$ which is gained (during charging) or lost (during discharging) by the TES material when its temperature changes from $\mathrm{T}_{1}$ to $\mathrm{T}_{2}$.

$$
Q_{s}=M \int_{T_{\mathrm{q}}}^{T_{\mathrm{a}}} C_{\rho} d T=V \int_{T_{\mathrm{n}}}^{T_{\mathrm{a}}} \rho C_{\rho} d T
$$

Whereby:

- $\mathrm{M}$, represent the mass $(\mathrm{kg})$ of the TES material

- $C_{\rho}$, represent the isobaric specific heat capacity $(\mathrm{J} / \mathrm{kg}$. ${ }^{\circ} \mathrm{C}$ ) of the TES material

- $d T$, is the differential temperature $\left({ }^{\circ} \mathrm{C}\right)$

- $V$, represent the volume $\left(\mathrm{m}^{3}\right)$ of the TES material

- $\rho$, represent the density $\left(\mathrm{kg} / \mathrm{m}^{3}\right)$ of the TES material

Although there are other several parameters that effect the performance of the energy storage system as described in the previous section such as thermal conductivity, vapor pressure, temperature equalization in the material etc. Eq. 1 shows that the sensible heat energy is largely dependent on the material's density and specific heat capacity.

a) Liquid media storage. Liquid media storage can be used either for heating or cooling purposes with water and thermal oil being the most popular liquid sensible heat storage material. Water is used in many applications including hotwater storage tanks for domestic and industrial heating. Other liquid media storage includes oil-based fluid and molten salts. Table 1 shows the thermal properties of some of the commonly used liquid media in sensible heat storage systems.

TABLE I. Thermal properties of widely used liquid materials for sensible heat storage $[11,12,13]$.

\begin{tabular}{|c|c|c|c|}
\hline Materials & Density $\left(\mathbf{k g} / \mathbf{m}^{\mathbf{3}}\right)$ & Specific Heat Capacity $(\mathbf{J} / \mathbf{k g} . \mathbf{K})$ & Temperature Range $\left({ }^{\circ} \boldsymbol{C}\right)$ \\
\hline Water & 1000 & 4190 & 0 to 100 \\
\hline Ethanol & 780 & 2460 & -117 to 79 \\
\hline Glycerin & 1260 & 2420 & 17 to 290 \\
\hline Engine Oil & 880 & 1880 & -10 to 160 \\
\hline Butanol & 809 & 2400 & Up to 118 \\
\hline Caloria HT 43 & 867 & 2200 & 12 to 260 \\
\hline Propanol & 800 & 2500 & Up to 97 \\
\hline Liquid Paraffin & 900 & 2130 & Up to 200 \\
\hline Molten salt & 1950 & 1570 & Up to 400 \\
\hline
\end{tabular}


For low temperature applications, water is seen as the best storage media of the available liquids due to several benefits listed below $[8,13]$ :

- Cheap and easily available.

- Easily handled and controlled, harmless and nonflammable.

- Has a reasonable high density, high specific heat capacity, and high thermal diffusivity.

- Can be used without a heat exchanger.

- The process of charging and discharging can easily occur at the same time.

- It can be stored in all kinds of containers and can easily mix with additives.

Although water is seen to have many desirable benefits, there are also disadvantages associated with using water as a storage media, such as $[8,13]$ :

- It is not desirable for medium and high temperature applications because it can only operate between $0{ }^{\circ} \mathrm{C}$ and $100^{\circ} \mathrm{C}$.

- At high temperature it is associated with high vapor pressure (above 5 bar).

- It can cause corrosion.
- Stratification is difficult to achieve.

Other liquid media such as ethanol and propanol can as well be used for low temperature applications, however they are highly flammable and not cost effective to implement. They require delicate handling which could increase the operational cost of the solar drying system if they are to be integrated in the energy storage system.

b) Solid media storage. In contrast to some of the disadvantages of water such as high vapor pressure and the limitations of other liquids, thermal energy can be stored as sensible heat in solids. For solid materials, soil and rock piles are the most commonly used storage materials due to their low cost and availability [8]. In general, solid storage materials are chemically inert, can store more energy than liquids, and have low vapor pressure. Thus, they can operate under no pressure containing vessel [13]. Because of their nature, when used in a thermal energy storage system, a fluid (usually air) is required to circulate and transfer the heat during charging and discharging process. This affects the thermal efficiency of the system since constant direct contact between the heat transfer fluid (air) and the solid material needs to be maintained [10]. Table 2 shows the thermal properties of some of the solid materials commonly used for thermal storage.

TABLE II. Thermal properties of solid materials used for sensible heat storage $[11,13]$

\begin{tabular}{|l|l|l|l|}
\hline Material & \multicolumn{1}{|c|}{$\begin{array}{c}\text { Density } \\
\left(\mathbf{k g} / \mathbf{m}^{3}\right)\end{array}$} & $\begin{array}{c}\text { Specific Heat } \\
\text { Capacity } \\
(\mathbf{J} / \mathbf{k g} . \mathbf{K})\end{array}$ & \multicolumn{1}{|c|}{$\begin{array}{c}\text { Thermal } \\
\text { Conductivity } \\
(\mathbf{W} / \mathbf{m} . K)\end{array}$} \\
\hline Aluminum & 2700 & 890 & 204 \\
\hline Iron & 7850 & 465 & 59.3 \\
\hline Copper & 8950 & 380 & 385 \\
\hline Wet Earth & 1700 & 2100 & 2.5 \\
\hline Dry Earth & 1260 & 795 & 0.25 \\
\hline Limestone & 2500 & 910 & 1.3 \\
\hline Granite & 3000 & 790 & 3.5 \\
\hline Concrete & 2240 & 1130 & $0.9-1.3$ \\
\hline Wood (oak) & 480 & 2000 & 0.16 \\
\hline Sandstone & 2200 & 710 & 1.8 \\
\hline Bricks & 1700 & 840 & 0.69 \\
\hline
\end{tabular}

The energy stored in TES systems utilizing these materials depend on many factors as discussed in previous sections such as thermophysical properties of the material, material size, and other heat transfer phenomena. Further details on solid materials for sensible heat storage can be found in the literature $[1,10,13,14,15]$.

2) Latent heat energy storage. Latent heat is described as the energy absorbed or released at a constant temperature when the material changes from one phase to another e.g from solid to gas, liquid to gas, or solid to liquid [7,8]. Although the transformation of a material to a gas phase is possible, it is not common in thermal energy storage because gas occupies large volumes which can lead to high costs and other limitations [18]. The materials that undergo phase changes are commonly known as phase change materials (PCMs) and normally the PCMs used in thermal energy storage undergo solid to liquid transformation and vice versa. Research indicates that the storage of latent heat is based on the latent heat of melting rather than the latent heat of vaporization and such systems 
provide a high energy storage density in comparison to sensible heat storage systems [16]. Table 3 shows some of the PCMs commonly used for thermal energy storage.

TABLE III. Phase Change Materials used in thermal energy storage $[11,16,17]$

\begin{tabular}{|c|c|c|c|}
\hline Materials & $\begin{array}{c}\text { Melting Point } \\
{ }^{\circ} \mathrm{C}\end{array}$ & $\begin{array}{r}\text { Density } \\
\mathrm{kg} / \mathrm{m}^{3}\end{array}$ & $\begin{array}{c}\text { Latent Heat } \\
\qquad 10^{6} \mathrm{~J} / \mathrm{m}^{3}\end{array}$ \\
\hline Paraffin wax & $58-60$ & 900 & $180-200$ \\
\hline Animal fat & $20-50$ & 900 & $120-210$ \\
\hline Salt hydrates: & & & \\
\hline $\mathrm{CaCl}_{2} .6 \mathrm{H}_{2} \mathrm{O}$ & 29 & 1802 & 190.8 \\
\hline $\mathrm{MgCl}_{2} \cdot 6 \mathrm{H}_{2} \mathrm{O}$ & 117 & 1569 & 168.6 \\
\hline $\mathrm{Mg}\left(\mathrm{NO}_{3}\right)_{2} .6 \mathrm{H}_{2} \mathrm{O}$ & 89 & 1636 & 162.8 \\
\hline $\mathrm{Ba}(\mathrm{OH})_{2} .8 \mathrm{H}_{2} \mathrm{O}$ & 78 & 2070 & 265.7 \\
\hline $\mathrm{Na}_{2} \mathrm{~S}_{2} \mathrm{O}_{3} .5 \mathrm{H}_{2} \mathrm{O}$ & 48 & 1750 & 200 \\
\hline
\end{tabular}

Despite the PCMs outlined in Table 3, The thermal storage materials listed in Table 3 and others such as such as esters, glycols, tatty acids, alcohols, nitrate salts, carbonate salts, chloride salts, metal and alloys, etc. are discussed in detail the literature. Thermal analysis during phase transition is generally described by Eq. 2 .

$$
\Delta Q=H_{2}-H_{1}
$$

Eq. 2, can be expanded into Eq. 3 as expressed below:

$$
\Delta Q=\int_{T_{\mathrm{i}}}^{T_{m}} m C_{p s} d T+m f \Delta q+\int_{T_{m}}^{T_{f}} m C_{p l} d T
$$

In Eq. 2, $\Delta \mathrm{Q}(\mathrm{J})$ is the energy absorbed or released and $\mathrm{H}$ is the enthalpy before and after transition. The enthalpy is related to latent heat and volume of the materials. In Eq. 3, Ti, Tf and Tm are the temperatures $\left({ }^{\circ} \mathrm{C}\right)$ at initial point, final point and melting point, respectively; $\mathrm{m}$ is the mass $(\mathrm{kg})$ of PCM; Cps is the specific heat capacity ( $\mathrm{kJ} / \mathrm{kg} . \mathrm{K})$ of the PCM during the solid phase (between $\mathrm{Ti}$ and $\mathrm{Tm}$ ); $\mathrm{Cpl}$ is the specific heat capacity (kJ/kg.K) of the PCM during the liquid phase (between Tm and $\mathrm{Tf})$; $\mathrm{f}$ is fraction melt; $\Delta \mathrm{q}$ is the change in latent heat $(\mathrm{J} / \mathrm{kg})$. Research indicates that in addition to the properties and characteristics discussed in section IIA, a thermal storage system utilizing a PCM needs to meet the following specific requirements $[7,13]$ :

- Must melt in the desired temperature range.

- Must have a high heat of melting or large enthalpy for phase change.

- Must be chemically stable for all the reversable thermal processes without significant loss in performance.

- Subcooling during freezing and supersaturation during melting of the PCM must be minimal with no segregation.

- The PCM must be thermally stable with a low vapor pressure for the operating temperature range.
- A suitable heat exchanger is required for the heat transfer process between the PCM and the system requiring heat.

Due to advancement in technology and research, composite phase change materials have been introduced in thermal energy storages. Their primary function is to enhance the thermal conductivity of regular PCMs which are generally associated with poor thermal conductivity [10]. The discussion of composite phase change material is beyond the scope of this paper but literature is available for further research. Overall, PCMs are usually preferred over sensible heat materials for thermal storages, mainly because:

- A thermal storage system using PCMs operates at more or less a constant temperature, thus, the thermal gradient during charging and discharging remains small.

- PCMs store more heat per unit volume, thus, less volume is required for storage.

- PCMs have high thermal storage capacity for small temperature difference.

- The use of a heat exchanger allows both charging and discharging phases to occur simultaneously.

3) Thermochemical storage. Technology advancement and ongoing researches have come up with ways to overcome the burdens and uncertainties present in sensible and latent heat energy storages. Part of the technology advancement is the use of thermochemical energy storage systems. Thermochemical energy storage systems depend on the energy that is absorbed and released as the result of a change in enthalpy of a completely reversable chemical reaction. In thermochemical storage system, the charging process is referred to as an endothermic mode in which energy is absorbed and stored within the chemical bonds. The discharging process is referred to as an exothermic mode in which energy is released [8]. These systems are mainly developed for storing energy in 
larger quantities than other type of TES systems and high temperatures are easily attainable due to faster reaction rates [13]. Research also indicates that energy losses in thermochemical storage systems are minimal and since the energy stored is mostly of great magnitude, they are commonly used in power plants for electricity generation. Hence, thermochemical energy storage is not of great advantage for low temperature application such as solar dryer systems. Detailed discussion on this type of TES system is not presented in this paper due to its complexity but there is extensive literature on the topic that can be consulted.

\section{Solar dryer systems with integrated TES system}

Sandali et al. (2018) investigated the thermal performance of a direct solar dryer with an integrated heat supply. Their study aimed to improve drying of the products by increasing the drying air temperature and promoting a continuous drying process during off peak hours using a geothermal water heat exchanger. The study found that the system was effective and significantly improved thermal performance of the solar dryer, particular during the night. The continuous use of geothermal water at constant temperature ensured there was a constant supply of heat for drying. However, one can economically utilize this system only in regions with geothermal water supply. Reyes et al. (2014) conducted a study on the performance evaluation of a heat exchanger that incorporated a solar energy accumulator. The heat exchanger used paraffin wax to store solar thermal energy and the wax was mixed with $5 \% \mathrm{w} / \mathrm{w}$ aluminum wool from recycled materials to improve thermal conductivity. Based on their results, $9.5 \mathrm{~kg}$ of paraffin wax was capable of storing $3000 \mathrm{~kJ}$ of energy which raised the temperature of $3.5 \mathrm{~m} 3 / \mathrm{h}$ air flow by $20{ }^{\circ} \mathrm{C}$ in 2 hours. They concluded that this TES could extend the drying process and could even be used for heating purposes in household applications. Rabha et al. (2017) conducted a study to evaluate the performance of a forced convection solar dryer with an integrated paraffin wax thermal energy storage system as shown by the photograph in Fig 2 .

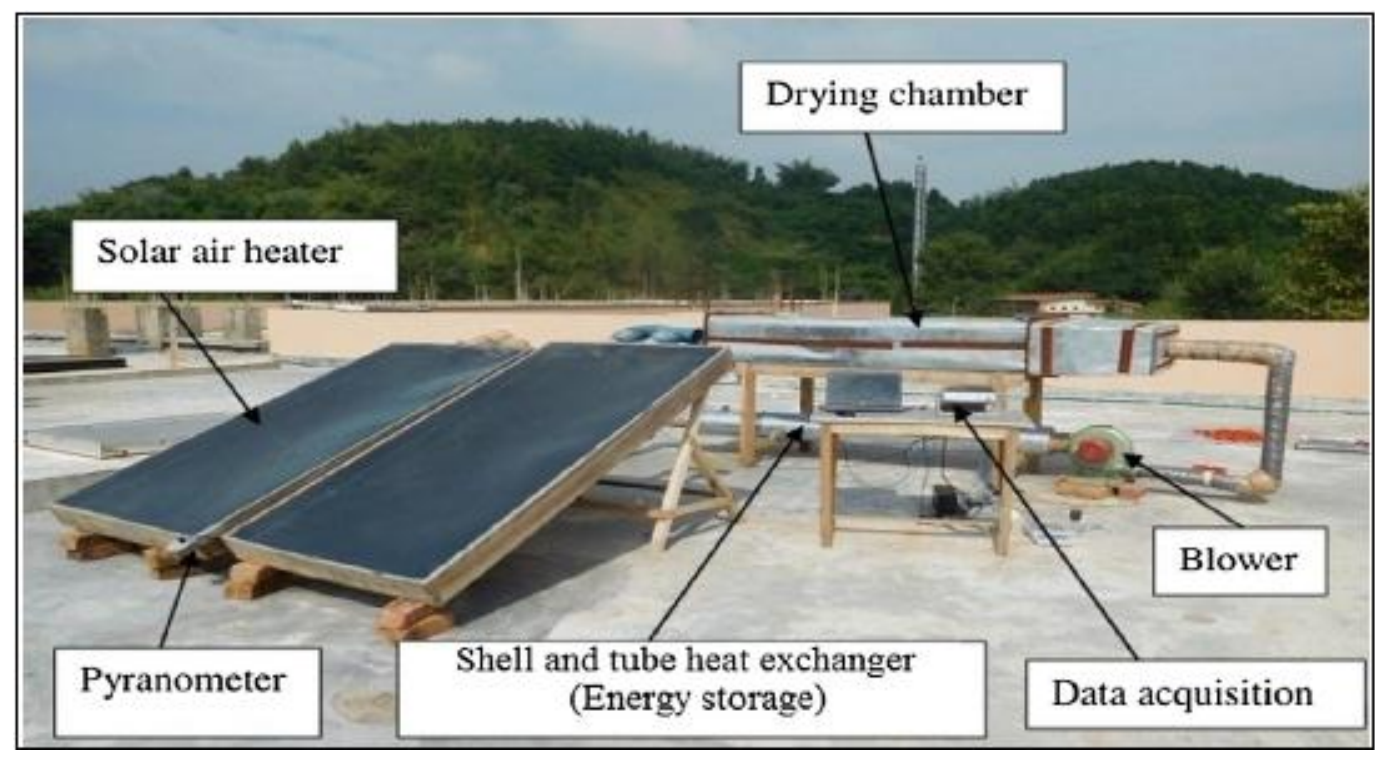

Fig. 2. Solar dryer system with integrated TES system [22].

As indicated in Fig 2, Rabha et al.'s dryer system consists of two double-pass solar air heaters to provide sufficient temperature to melt the paraffin wax. The wax is housed in a heat exchanger of shell and tube type. The test was conducted by drying a $20 \mathrm{~kg}$ batch of red chilli in which the moisture content of red chilli was reduced from $73.5 \%$ (wet basis) to $9.7 \%$ (wet basis) in 4 days. Their study concluded that the system is effective in improving the thermal efficiency and providing a constant drying temperature during the cloudy period. However, with the addition of a second solar collector, costs were increased and drying period seemed to be longer. This can motivate the need for further improvements on the drying rate and lowering of the costs by eliminating the need for a two-double pass solar air heater.

Mohanraj et al. (2009) carried out a study on drying chilli. They analyzed the performance of a solar dryer system which incorporated a TES system that used gravel as a heat energy storage material. As shown in Fig 4, the solar dryer system is composed of a solar air heater with a heat storage unit, a drying chamber and a blower. The solar air heater is composed of a glass cover and commercially black painted copper absorber plate. In between the absorber plate and the insulation there is a gap which is filled with sand particles mixed with aluminum scraps for thermal storage during peak hours and to obtain hot air during off peak hours of the day. The drying chamber was designed with a capacity of holding $50 \mathrm{~kg}$ of chilli per batch. The solar air heater was inclined at an angle of $25^{\circ}$ with respect to horizontal. They conducted the experiment at an air flow rate of $0.25 \mathrm{~kg} / \mathrm{s}$ and managed to lower the moisture content of chilli from an initial moisture content of $72.8 \%$ (wet basis) to a final moisture content of about $9.2 \%$ and $9.7 \%$ (wet basis) in just 24 hours. The incorporation of a heat storage unit to the dryer system was found to be effective in improving the performance of the system and prolonged the drying process by 4 hours per day. Thermal efficiency was found to be about $21 \%$. 


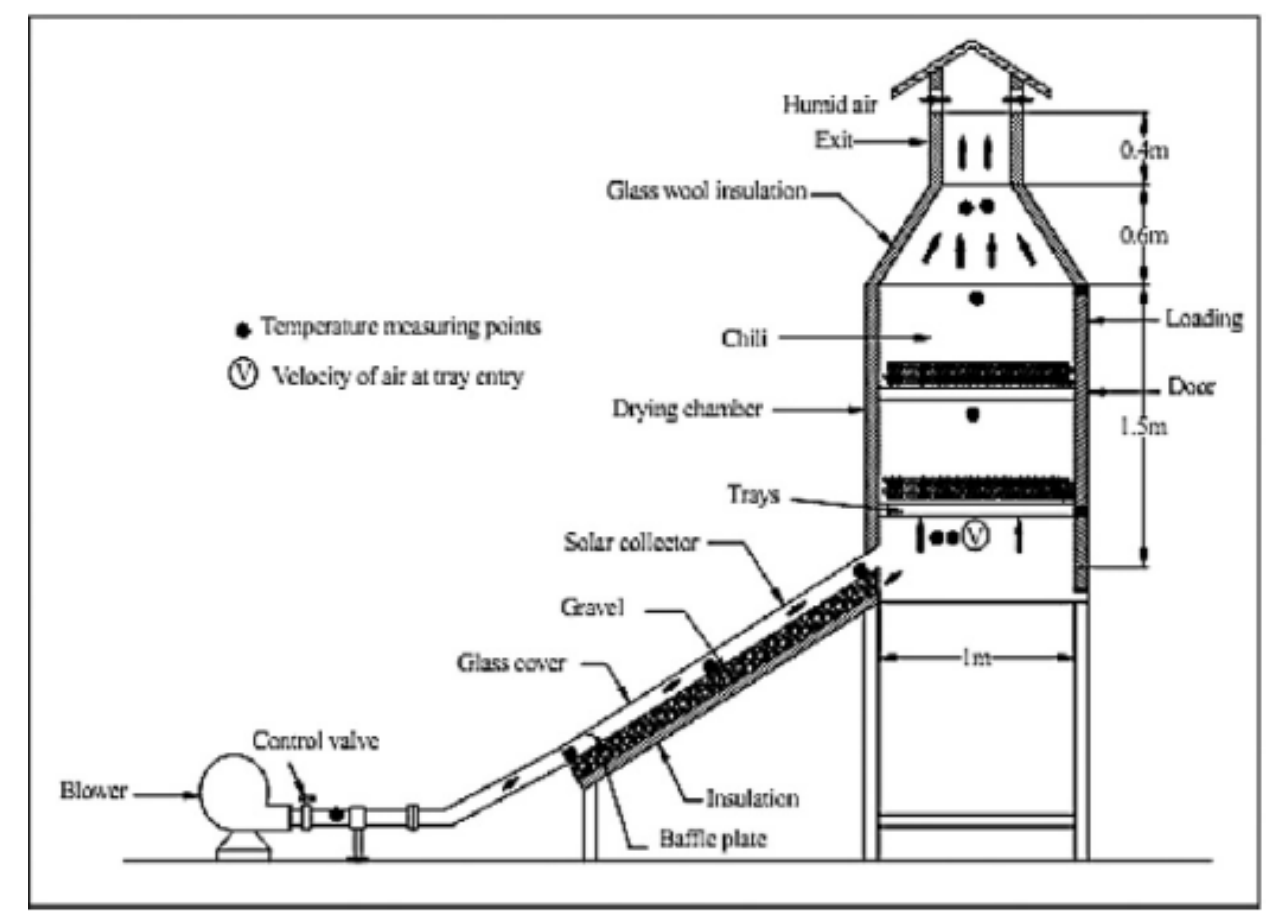

Fig. 4. Schematic view of the experimental setup [23]

Ayyappan et al. (2015) conducted an experiment to improve the thermal performance of a natural convection solar greenhouse dryer using concrete, sand and rock as sensible heat storage materials. Various experimental trials were run for different materials and they found that for both sand and rock a 4-inch thickness layer was the optimum solution to provide better drying during the day and night. Coconut was used as the drying product during the experiment. When concrete was used to store heat energy, the dryer system was able to lower the moisture content of coconut from $52 \%$ (wet basis) to $7 \%$ (wet basis) in 78 hours in comparison to open sun drying which takes 174 hours. This indicated a saving of drying time by about $55 \%$. When heat energy was stored using sand, the drying time of coconut was reduced to 66 hours with a saving of $62 \%$ of drying time as compared to open sun drying. If rock was used, the drying time was further reduced to 53 hours, saving the drying time by about $69 \%$. According to their results, rock provided the highest thermal efficiency of $11.65 \%$ while sand yielded the least thermal efficiency of $9.5 \%$. An experimental study conducted by Hailu et al. (2017) on storage of solar thermal energy using sand-bed storage for seasonal space heating applications as shown by the schematic in Fig. 5. Their main idea was to address cold winter climate issues by ensuring solar energy is stored as heat during summer and recovered for house heating during the long freezing temperatures of winter. Water is heated inside a solar collector

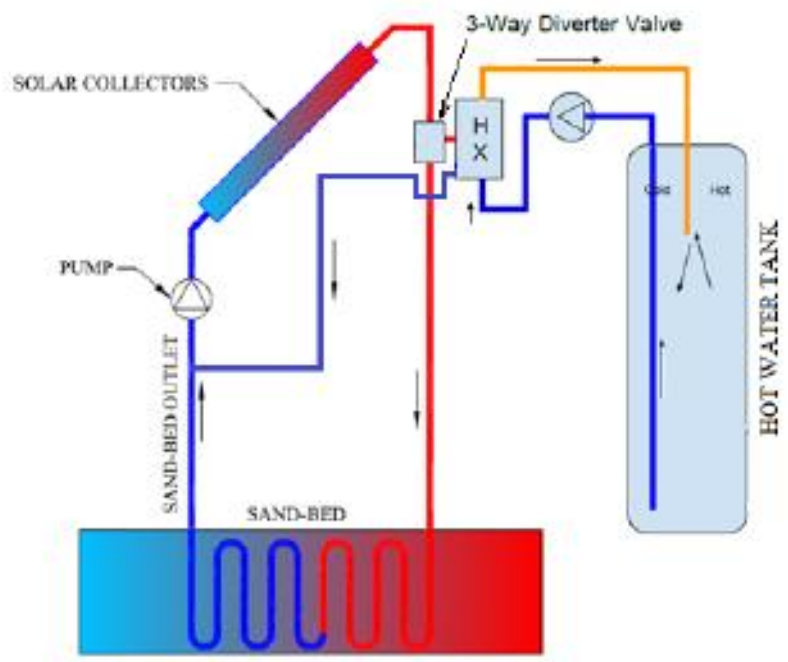

Fig. 5. Schematic diagram of a seasonal pace heater using solar thermal energy sand-bed storage [21] 


\section{CONCEPTUAL DESIGNS}

In order to improve drying efficiency of a solar dryer, one needs to look into ways of increasing its drying capacity and minimizing thermal energy loses. One of the cheapest and yet most effective way to increase drying capacity of a solar dryer is to incorporate a TES system which can be used during low or off-peak sunshine hours. As discussed in the preceding section, thermal energy can be stored in many ways. Considering various factors of selecting a suitable TES material as discussed in section IIA, two conceptual designs are proposed and considered to be economically effective in aiding solar drying. The first concept is based on the use of rocks to store solar thermal energy while the second one relies on the use of heated water to store solar thermal energy

\section{A. Concept 1: Rock Bed Solar Thermal Energy Storage}

The use of rocks as a thermal storage material has many advantages such as low cost to implement and maintain. Depending on the application, various types of rocks can be used to store thermal energy; granite, gravel or limestone are frequently used as thermal storage materials in food dryers [26]. Rocks have poor thermal conductivity, allowing them to store heat for relatively longer periods. However, they have a fairly low specific heat capacity which makes them suitable only for storing heat for low temperature applications such as food drying in solar dryer systems. Fig. 6 shows the design layout of the proposed rock bed TES system that harvests and stores solar energy. This system is designed as a standby unit for a solar dryer system which will supply hot air to the drying chamber for drying during off-peak periods such as cloudy hours or nighttime.

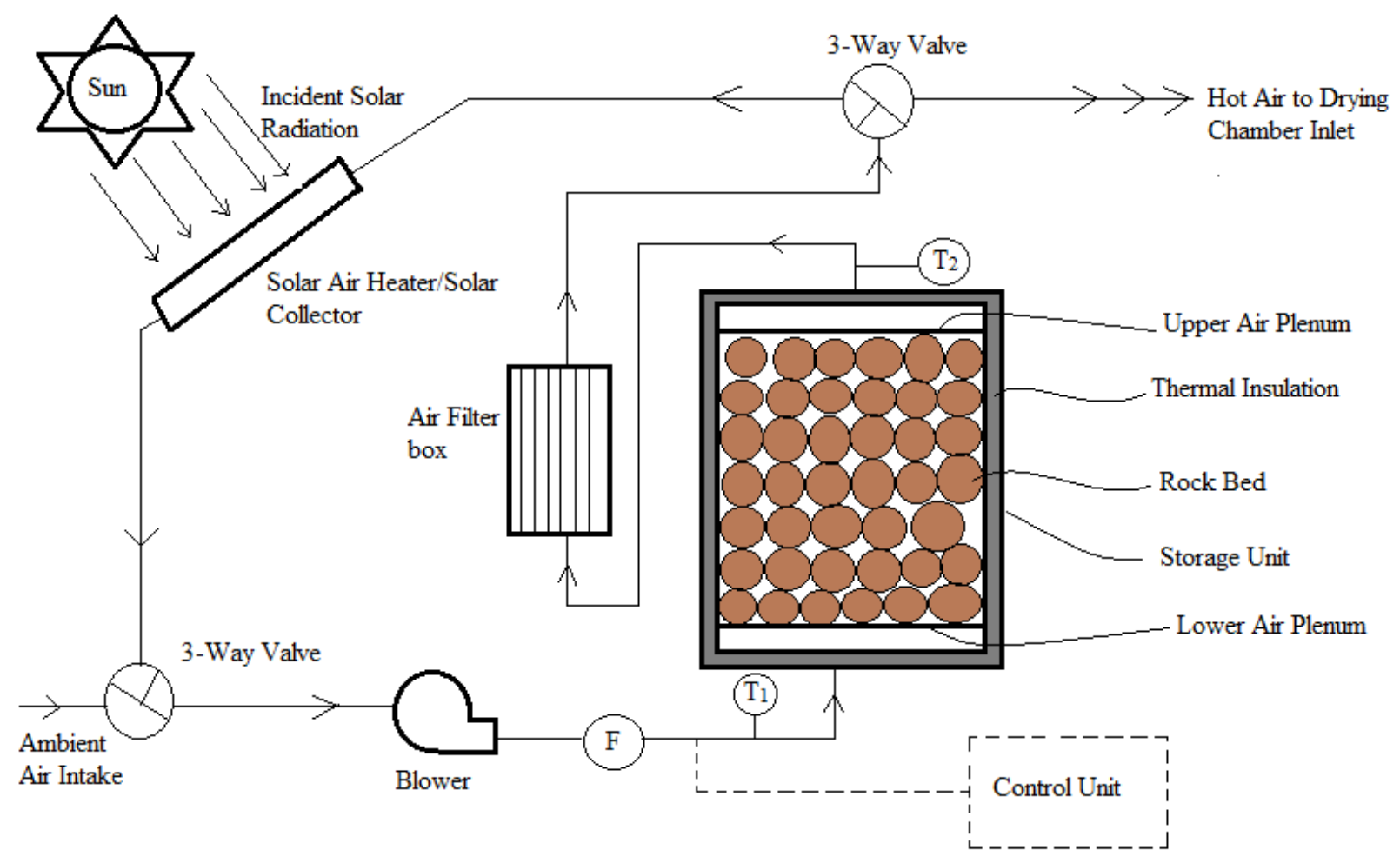

Fig. 6. Conceptual design layout for the rock bed solar thermal energy storage system

The working fluid of the system is air, which is heated in the solar collector as a results of the incident solar radiation. The system can work on its own independent solar collector or hot air can be channeled from the outlet(s) of the solar collector for the solar dryer system. Hot air is sucked and blown by the blower into the storage unit where heat is absorbed and stored in the rock bed due to the heat transfer process. The storage unit is covered with a thermal insulation layer to prevent any heat loss. The system is designed with an air filter box to ensure that small rock particles or debris do not clog the control valves or enter the drying chamber where food products are dried. Three-way control valves are positioned within the system flow network to control the air flow during the processes of charging and discharging of the TES system.

It is also proposed that such a system can have a flow control meter (denoted "F") to monitor the air flow rate. Temperature sensors "T1" and "T2" are also essential in the system to monitor the temperature across the storage unit. The entire TES system can be electronically controlled to ensure the working fluid is optimally circulated during charging and discharging phases. Magdalena et al. [26] conducted an experiment using granite spheres of three different sizes as materials to fill the bed storage. Based on their findings, the drying process was prolonged by two hours which indicates in improvement in the drying process. It is however noted that 
efficiency of such thermal storage systems is affected by the sizes of materials, inlet air temperature and air flow rate.

\section{B. Concept 2: Hot water tank for Solar Thermal Energy Storage}

Water is one of the cheapest heat storage materials used in low temperature (not more than $100{ }^{\circ} \mathrm{C}$ ) applications such house space heating, car interior heating and hot water supply for various applications [10]. It has many favorable advantages such as easy availability and high specific heat capacity in comparison with other sensible heat materials such as rocks, sands, mineral oil, etc. Apart from many favorable advantages as discussed section IIB1a, storing thermal energy using water also possesses disadvantages such as corrosiveness and high vapor pressure which one could possibly control. A schematic of the design layout of the proposed solar TES system that uses a hot water tank for thermal storage is shown in Fig. 7. This conceptual design represents a standby thermal storage system which can be coupled to a food drying system such a solar grain dryer to provide intermittent thermal energy support to the drying process.

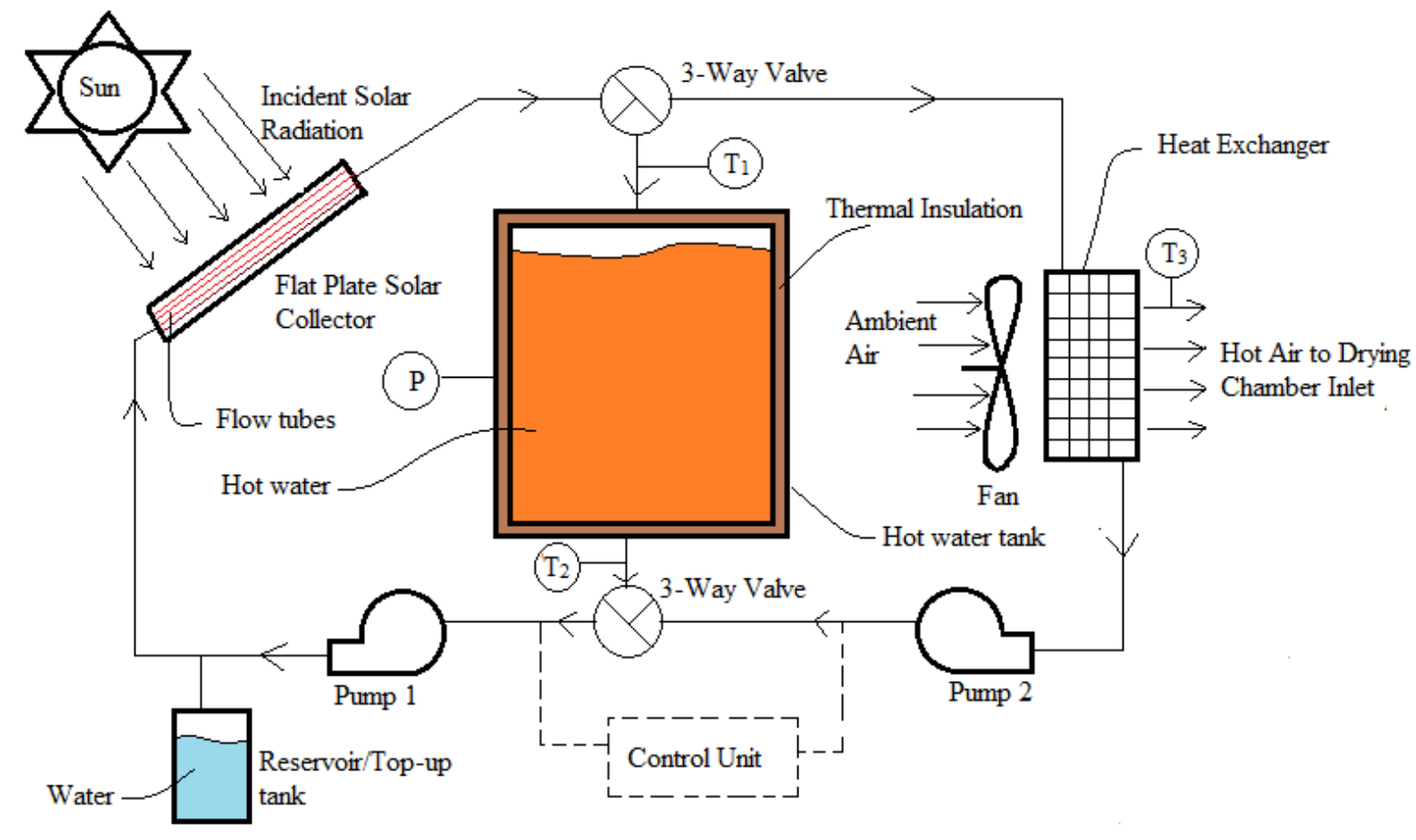

Fig. 7. Conceptual design layout for the hot water tank solar thermal energy storage system

This system is designed similarly to the one with the rock bed TES system as discussed in section IIIA. During peak hours of the day, the working fluid (water) is heated (charging phase) to a high temperature inside the flat plate solar collector as a result of the heat transfer process between the cool water and heated flow tubes. The hot water is pumped (by pump 1) and circulated between the flat plate solar collector and a thermally insulated hot water tank where it is stored. During off-peak hours, hot water from the tank can be pumped (by pump 2) and circulated between the tank and a heat exchanger where heat is transferred from the water to air (discharging phase). A fan can be incorporated in the system to induce forced convection over the heat exchanger which enhances the heat transfer process. The hot air exiting the heat exchanger can be channeled to the drying chamber where products such as foods can be dried. The flow of the working fluid in the entire system can be electronically controlled through control valves and feedback sensors. As a safety precaution, a pressure relief valve (denoted "P") can be included to control the pressure inside the hot water tank. While the temperature sensors denoted "T1", "T2" and "T3" are crucial in monitoring the temperatures across the hot water tank and that of the hot air, respectively.

\section{Conclusion}

A study was conducted on the utilization of thermal energy storage materials with an emphasis on the optimization of solar dryer systems for drying food products. Different materials aimed at storing thermal energy were discussed and suitable materials for solar drying applications were considered. Two conceptual design layouts were considered as economically viable solutions to improve thermal efficiency of solar dryer systems and prolong the drying process, namely, concept 1 which uses a bed of rocks to store solar thermal energy, and concept 2 that uses water to store solar thermal energy. Both energy storage materials are charged during peak hours of the day and discharged during off-peak hours when it is necessary. These were considered as viable concepts for the intended application, and further research can be put in place to determine the best of two. In conclusion, for low temperature applications, a well-designed thermal energy storage unit that utilizes an energy storage media such as water or rocks can be used for the optimization of food solar dryers. 


\section{Recommendations}

This paper gives preliminary indications that solar dryer systems can be optimized with suitable thermal energy storage materials. Due to the limit of the scope of this study, it is recommended that further research be conducted with experimental studies of the two conceptual designs discussed in the paper.

\section{REFERENCES}

[1] A. Saxena, Varun, and A.A. El-Sebaii. "A thermodynamic review of solar air heaters," Renewable Sustainable Energy Rev., vol. 43, pp. 863-890, 2015. https://doi.org/10.1016/j.rser.2014.11.059.

[2] K. Kant, A. Shukla, A. Sharma, A. Kumar, and A. Jain. "Thermal energy storage based solar drying systems: A review," Innovative Food Sci. Emerg. Technol., vol. 34, pp. 86-99, 2016, https://doi.org/10.1016/j.ifset.2016.01.007.

[3] M.L. Bal, S. Satya, and N.S. Naik. "Solar dryer with thermal energy storage systems for drying agricultural food products: A review," Renewable Sustainable Energy Rev., vol. 14, no. 8, pp. 2298-2314, 2010. https://doi.org/10.1016/j.rser.2010.04.014.

[4] South Africa. Department of Energy. Renewable Energy Solar Power, 2017. http://www.energy.gov.za/files/esources/renewables/r_sol ar.html.

[5] I. Sarbu and C. Sebarchievici. "A comprehensive review of thermal energy storage," Sustainability, vol. 10, no. 1, p. 191, 2018. https://doi.org/10.3390/su10010191.

[6] L. Vikramjose. "A review on solar drying process with thermal energy storage system," Int. Res. J. Eng. Technol., vol. 5, no. 6, pp. 1859-1862, 2018. https://www.irjet.net/volume5-issue6.

[7] Flood, M. Solar Prospects: The Potential for Renewable Energy. London: Wildwood House, 1983.

[8] G.N. Tiwari and S. Suneja. Solar Thermal Engineering Systems. London: Narosa Publishing House, 1997.

[9] D. Lefebvre. and F.H. Tezel. "A review of energy storage technologies with a focus on adsorption thermal energy storage processes for heating applications" Renewable Sustainable Energy Rev. vol. 67, pp. 116-125, 2017. DOI: 10.1016/j.rser.2016.08.019.

[10] G. Alva, L. Liu, X. Huang, and G. Fang. "Thermal energy storage materials and systems for solar energy applications," Renewable Sustainable Energy Rev., 68, 2017, pp. 693-706. https://doi.org/10.1016/j.rser.2016.10.021.

[11] C.J. Chen. Physics of Solar Energy. New York: John Wiley \& Sons, 2011.

[12] A. Sharma, V.V. Tyagi, R.C. Chen, and D. Buddhi. "Review on thermal energy storage with phase change materials and applications," Renewable Sustainable Energy Rev., vol. 13, no. 2, pp. 318-345, 2009. https://doi.org/10.1016/j.rser.2007.10.005.

[13] T. Bauer, W. Steinmann, D. Laing, and R. Tamme. Chapter 5: Thermal Energy Storage Materials and Systems. In: Annual Review of Heat Transfer, 15, pp. 131-177, 2012.2 DOI: 10.1615/AnnualRevHeatTransfer.2012004651.

[14] A. Abhat. "Low temperature latent heat thermal energy storage: Heat storage materials," Solar Energy, vol. 30, no. 4, pp. 313-332, 1983. https://doi.org/10.1016/0038092X(83)90186-X.

[15] M.S. Hasnain. "Review on sustainable thermal energy storage technologies, Part I: heat storage materials and techniques," Energy Convers. Manage., vol. 39, no. 11, pp. 1127-1138, 1998. https://doi.org/10.1016/S01968904(98)00025-9.

[16] H.P. Garg, S.C. Mullik, and A.K. Bhargava, Solar Thermal Energy Storage. Dordricht: D. Reider Publishing Company, 1985.

[17] M.M. Farid, M.A. Khudhair, A.S Razack, and S AlHallaj. "A review on phase change energy storage: materials and applications," Energy Convers. Manage., vol. 45, no. 9, 1597-1615, 2004. https://doi.org/10.1016/j.enconman.2003.09.015.

[18] C. Bruno and L. Noel. "High temperature latent heat thermal energy storage: Phase change materials, design considerations and performance enhancement techniques," Renewable Sustainable Energy Rev., vol. 27, pp. 724-737, 2013. https://doi.org/10.1016/j.rser.2013.07.028.

[19] A. Reyes, D. Negrete, A. Mahn, and F. Sepulveda. "Design and evaluation of a heat exchanger that uses paraffin wax and recycled materials as solar energy accumulator," Energy Convers. Manage., vol. 88, pp. 391398 ,

2014. https://doi.org/10.1016/j.enconman.2014.08.032.

[20] M. Sandali, A. Boubekri, D. Mennouche, and N. Gherraf. "Improvement of a direct solar dryer performance using a geothermal water heat exchanger as supplementary energetic supply. An experimental investigation and simulation study," Renewable Energy, vol. 135, , pp. 186196, 2019. https://doi.org/10.1016/j.renene.2018.11.086.

[21] G. Hailu, P. Hayes, and M. Masteller. "Seasonal solar thermal energy sand-based storage in a region with extended freezing periods: Par I Experimental investigation," Energies, vol. 10, no. 11, p. 1873, 2017. https://doi.org/10.3390/en10111873.

[22] D.K. Rabha and P. Muthukumar. "Performance studies on a forced convection solar dryer integrated with a paraffin wax-based latent heat storage system," Solar Energy, vol. 149, pp. 214-226, 2017. DOI: 10.1016/j.solener.2017.04.012.

[23] M. Mohanraj, and P. Chandrasekar. "Performance of a 
International Journal of Engineering Research and Technology. ISSN 0974-3154, Volume 13, Number 10 (2020), pp. 2803-2813

(C) International Research Publication House. https://dx.doi.org/10.37624/IJERT/13.10.2020.2803-2813

forced convection solar drier integrated with gravel as heat storage material for chili drying," J. Eng. Sci. Technol., vol. 4, no. 3, pp. 305-314, 2009. http://jestec.taylors.edu.my/V4Issue3.html.

[24] S. Ayyappan, K. Mayilsamy, and V.V. Sreenarayanan. "Performance improvement studies in a solar greenhouse drier using sensible heat storage materials," Heat Mass Transfer, vol. 52, no. 3, pp. 459-467, 2016. DOI: 10.1007/s00231-015-1568-5.
[25] S.F. Dina, H. Ambarita, F.H. Napitupulu, and H. Kawai. "Study on effectiveness of continuous solar dryer integrated with desiccant," Case Stud. Therm. Eng., vol. 5, pp. 32-40, 2015. https://doi.org/10.1016/j.csite.2014.11.003.

[26] N. Magdalena, N. Artur, and Pawel, P. A granite bed storage for a small solar dryer. Materials, vol. 11, no. 10, p. 1969, 2018. https://doi.org/10.3390/ma11101969G. 